\title{
Antibiotic use on crops in low and middle-income countries based on recommendations made by agricultural advisors
}

Philip Taylor ${ }^{*}(1)$ and Robert Reeder

\begin{abstract}
Background: Microbial resistance to medically important antibiotics is of international concern. There is considerable attention paid to the medical and veterinary use of antibiotics but there is a paucity of data on their use in global crop production. The only well documented use of antibiotics on crops is that on top fruit in the USA. Due to the absence of other data it is generally assumed that this use comprises the bulk of antibiotics applied to plants. The goal of this study was to investigate the scale and diversity of antibiotics being recommended for managing crop health problems in LMICs and the crops and types of problems for which they are selected.
\end{abstract}

Methods: Plantwise is an international program which assists with the provision of agronomic advice to smallholder farmers in LMICs. Recommendations relating to the management of crop problems are stored in an international database, comprising over 400,000 records collected over 8 years. The extent of antibiotic use in crop production when grouped by the $\mathrm{WHO}$ regions was analysed using descriptive statistics.

Results: Within our data all WHO regions of the world are using antibiotics on crop plants with the exception of Africa (no data for Europe) and the main crop on which they are used is rice. In some years, and in one region, nearly $10 \%$ of the management recommendations for rice contained an antibiotic. Eleven antibiotics are being recommended on crops (often blended together) and there is considerable regional variation as to where they are used. The problems against which antibiotics are recommended are extremely varied and we speculate that they are often used as a prophylactic spray to prevent, or control, low levels of bacterial disease.

Conclusions: The data reveals that antibiotics are being recommended far more frequently and on a much greater variety of crops than previously thought. Relative to medical and veterinary use the quantities used globally are comparatively small, but this niche does provide some unique avenues by which resistance could develop in human pathogens. Results presented here have implications for those wanting to limit the spread of antibiotic resistance.

Keywords: Antibiotics, Antibiotic resistance, Crop protection, Plant clinics, Plantwise, LMIC, Agricultural-advisors, Extension

\section{Background}

Whist the use and abuse of antibiotics in medical and veterinary arenas is well documented the use of antibiotics

*Correspondence: p.taylor@cabi.org

CABI-EUK Bakeham Lane, Egham TW209TY, UK in horticulture and plant agriculture is less well studied, but is an emerging area of concern (World Health Organization, Food and Agriculture Organization of the United Nations, World Organisation for Animal Health 2018). Antibiotic use in crop production is an emotive and 
controversial topic, not only because of safety concerns for the operator and the consumer (Gusberti et al. 2015) but more generally, for fears that antibiotic resistance to medically important antibiotics might be transferred to human pathogens. Proponents of the use of antibiotics in crop production point out that despite widespread use of antibiotics, for over half a century, there have been no reports of adverse effects in human health or persistent impacts on the environment (Stockwell and Duffy 2012). Where resistance to antibiotics in populations of phytopathogenic bacteria has developed, it is generally thought to have occurred through horizontal gene transfer from epiphytic commensal microorganisms (Sundin and Wang 2018). This is particularly relevant because identical broad host range plasmids carrying antibiotic resistance genes have been found in both plant pathogens and human pathogens (Sundin and Wang 2018; Palmer et al. 1997; Yau et al. 2010) raising concerns over possible transfer of resistance to animal and human pathogens.

A recent joint investigation by Food and Agriculture Organisation (FAO), World Organisation for Animal Health (OIE) and World Health Organisation (WHO) into antibiotic use found that the numbers of countries that are currently monitoring the use of antibiotics in crop cultivation is very low compared to those monitoring antibiotic use in the veterinary and medical arenas (FAO and WHO 2019a). Furthermore, out of the 158 countries questioned, only 3\% indicated they had any kind of regular assessment of the types and amounts of antibiotic use on crops (FAO and WHO 2019a). This contrasts strongly with countries that have monitoring systems in place for human use $(26 \%)$ and animal health (23\%). Overall $83 \%$ of the countries questioned indicated they had no means of assessing antimicrobial use on plants, or failed to respond and $11 \%$ considered they could only attempt to estimate antimicrobial use on crops based on national or regional sales (FAO and WHO 2019a).

Estimates of global antibiotics use in both animal and crop agriculture are hampered by a lack of reliable data. Gaps in the knowledge of the quantities of antibiotics used in animal production are considerable and data from high income countries (HICs) have been extrapolated and used to infer consumption by the remainder of the globe (Van Boeckel et al. 2015). Figures quoted by the Wellcome Trust estimate the use in agriculture to be between $63 \mathrm{k}$ and $240 \mathrm{k}$ tons per year (O'Neill 2015). The proportion of this figure used on crops is unknown, but believed to be low at between 0.26 and $0.5 \%$ of the estimated quantity (McManus et al. 2002; McManus 2014). However, in some localised and extreme cases, the amount of antibiotics used in crop-based agriculture has been estimated to be 700 times that used in human medicine (Rodríguez Sánchez 2008). In many HICs the use of antibiotics on crops is prohibited or regulated, however the permitted use of antibiotics on crops can be widescale, for example, at the beginning of 2019, in response to an outbreak of citrus greening, the US Environmental Protection Agency proposed treating the US citrus crop with up to 292 tons of streptomycin each year. By comparison, American medicine uses annually around 6.3 tons of aminoglycosides, the class of antibiotics that includes streptomycin (Jacobs 2019).

When reviewing the literature it is apparent that crop production is often not represented in multisector working parties set up to address antibiotic resistance. Many reports discussing antibiotic resistance in agriculture are entirely about antibiotic use in a veterinary setting and only mention crop production in passing. Furthermore, these reports often combine antibiotic resistance with antimicrobial resistance in general, which for plants would logically include fungicides. Fungicide use and resistance to fungicides is an important issue, however it is a separate one to antibiotic use and antibiotic resistance.

The concern over the spread of antibiotic resistance in agriculture, focuses on the use of antibiotics in animal care and the antibiotics inadvertently entering the environment as waste. It has been estimated that $90 \%$ of antibiotics used in animal health care may be excreted un-metabolised in the manure (FAO 2017). However, in crop production the antibiotics are not inadvertently entering the environment, they are deliberately sprayed over vast areas in the wider environment. The environmental fate and longevity of antibiotics entering a manure pile and those being sprayed onto crops are rather different, as would be their impact on the microbiology of the environment (McManus et al. 2002).

Control of phytopathogenic bacteria is an important aspect of growing many crops, and although the scale of antibiotics used in crop-based agriculture is not well documented, in some cropping systems they can be an effective method of controlling bacterial plant pathogens (Gusberti et al. 2015; Patil and Naik 2017). The most widely documented use of antibiotics on crops is in north America against the bacterial pathogen Erwinia amylovora, the cause of fire blight. This use has led to the claim that streptomycin is the most used antibiotic for plant disease control around the world, followed by oxytetracycline, which is used where resistance to streptomycin has developed (Sundin and Wang 2018). There are reports of other antibiotics being used in agriculture, such as gentamicin in Mexico and Costa Rica, oxonilic acid in Israel and kasugamycin in Japan and other Asian countries. However, with minor exceptions, (Rodríguez Sánchez 2008; Zhang et al. 2017; Wan 
et al. 2019) there are very limited data available on the extent of their use, on which crops and problems they are used against.

Plantwise (https://www.plantwise.org/) is an agricultural development programme that provides support and training to plant-based agricultural extension services in 33 countries in Africa, Asia and the Americas. Plantwise helps to train extension workers to provide Integrated Pest Management (IPM), advice to farmers and to work with national partners, usually state-run extension services, to establish networks of local plant clinics. Clinics are run by trained extension staff (referred to as plant doctors) and these are places where farmers can bring diseased or infested crop samples and obtain a diagnosis and practical plant health advice on written (or electronic) 'prescription forms' (Danielsen and Matsiko 2016; https://www.plantwise.org/about/). Based on examination of the plant sample and dialog with the farmer, all aspects of the problem are recorded (crop, developmental stage, part affected, symptoms, severity) along with details of the interaction that took place (location, date, farmer's contact details). This information is recorded either on a tablet or a paper form (which is later digitized). The information is uploaded into the international database known as the Plantwise Online Management System (POMS). Each country's data is held separately in the database and is only accessible to representatives from that country and the Plantwise programme. This database provides an overview of the plant health problems for which farmers seek assistance at plant clinics and the management solutions provided by plant doctors. It is this large repository of information that was investigated to assess antibiotic use.

\section{Materials and methods}

We used the POMS as the information source for this global investigation into antibiotic recommendations made by agricultural advisors. The data analysed were from the 32 countries for which there were over 100 records, covering the period 2012 -October 2018. These are listed below according to the WHO groupings; Africa, Americas, Eastern Mediterranean (EM), South East Asia (SEA) and Western Pacific (WP) (Table 1). Because of potential sensitivities surrounding the recommendation of antibiotics, the data has been grouped into regions and is not presented on a per country basis. Plantwise also operates in China, but data is not disclosed directly to CABI and does not appear the POMS database. All references to the use of antibiotics in China is from published literature, the data for some of which was gathered through Plantwise.

Before analysis, translations of crop names written in non-English languages were undertaken and the data harmonised to standardize the crop names e.g. 'rice' and 'paddy' were combined to; 'rice.' The diagnosis is recorded in a free-text field and via predefined check-boxes which allow the type of organism to be recorded e.g. 'bacteria', 'virus', 'nematode' etc. There are 11 checkboxes indicating a pathogen or pest (plus an 'unknown' and 'other'). The recommendation is also recorded in a free-text field, and it is here where the crop advisor suggests a course of action to remedy the plant health problem that may include an antibiotic. The data were meticulously analysed up until 2016 through a word erosion technique which removed punctuation, and stop words in order to make data relating to antibiotic use easier to collate. The antibiotics found during this initial search (2012-2016)

Table 1 The WHO groupings of the countries in which Plantwise is operational and collecting data

\begin{tabular}{|c|c|c|c|c|}
\hline Africa & Americas & Eastern Mediterranean & South East Asia & Western Pacific \\
\hline Burkina Faso & Barbados & Afghanistan & Bangladesh & Cambodia \\
\hline $\begin{array}{l}\text { Congo Democratic } \\
\text { Republic }\end{array}$ & Bolivia & Pakistan & India & Vietnam \\
\hline Ethiopia & Brazil & & Myanmar & China $^{a}$ \\
\hline Ghana & Costa Rica & & Nepal & \\
\hline Kenya & Grenada & & Sri Lanka & \\
\hline Malawi & Honduras & & Thailand & \\
\hline Mozambique & Jamaica & & & \\
\hline Rwanda & Nicaragua & & & \\
\hline Sierra Leone & Peru & & & \\
\hline Tanzania & Trinidad and Tobago & & & \\
\hline \multicolumn{5}{|l|}{ Uganda } \\
\hline Zambia & & & & \\
\hline
\end{tabular}

Countries with less than 100 records in the database were excluded from the analysis

a Data from China is collected but is not included in the POMS database 
and the tradenames thereof, provided the search terms to analyse the remainder of the data set (2016-2018). The internet was surveyed for antibiotic-containing products for plant use and these names were incorporated into searches within the data. Whilst most of the records were in English some were in other Latin languages and some were not in the Latin alphabet (21,336 records, approx. $5 \%)$. Although some of the spellings were ambiguous it was generally clear what was intended and even when non-Latin script was used, the names of the antibiotics were often recognisable as they were usually written in English. Despite extensive efforts, it is possible that some trade names written in foreign language could have been missed.

For this paper an antibiotic was considered to be a chemical that has anti-bacterial properties and has been extracted from a microbial source. Products not included in the analysis were those where the term "antibiotic" referred to a disinfectant, veterinary use (occasionally advice on animal disease is requested at plant clinics), or where the control measure was a biological control product, which has its effect through the production of antibiotics.

\section{Data analysis}

Antibiotic recommendations were recorded from 17 of the 32 countries analysed, of these 17 countries, 3 had only one record and 3 had less than 10 records. These countries were therefore excluded from further analysis. The remaining 11 countries (representing 4 of the WHO regions), were taken for further detailed analysis (Table 2).

\section{Results}

Where are antibiotics being used?

The entire dataset for the 32 countries comprised 436,674 records, of these the proportion that contained a recommendation for an antibiotic accounted for just $0.38 \%$ (Table 3). However, it was notable that there were large regional and country differences in the recommendation of antibiotics. For example, there were no records of antibiotic use on crop plants in any of the 12 African countries. After excluding all countries that do not recommend antibiotics on crops the proportion of records containing an antibiotic increased to $0.66 \%$. In ascending order, the recommendations of antibiotics, by proportion

Table 2 Regional breakdown of POMS data used in the analysis

\begin{tabular}{llll}
\hline WHO region & $\begin{array}{l}\text { Total number of countries } \\
\text { within the region }\end{array}$ & $\begin{array}{l}\text { Number of countries represented } \\
\text { in the POMS database }\end{array}$ & $\begin{array}{l}\text { Number of countries } \\
\text { per region included } \\
\text { in the analysis }\end{array}$ \\
\hline Africa & 46 & 12 & 0 \\
Americas & 35 & 10 & 3 \\
Western Pacific & 28 & 2 & 2 \\
Eastern Mediterranean & 21 & 2 & 1 \\
South East Asia & 11 & 6 & 5 \\
\hline
\end{tabular}

Breakdown of the total number of countries within the various WHO regions, their occurance in the POMS database, and the numbers found to be recommending antibiotics

Table 3 Antibiotic use in the various regions of the world expressed as a proportion of records

\begin{tabular}{lllll}
\hline WHO global region & $\begin{array}{l}\text { Number of countries } \\
\text { recommending } \\
\text { antibiotics }\end{array}$ & $\begin{array}{l}\text { Proportion } \\
\text { of Plantwise countries } \\
\text { of the region } \\
\text { recommending } \\
\text { antibiotics }\end{array}$ & $\begin{array}{l}\text { Numbers of records } \\
\text { containing antibiotic } \\
\text { recommendations }\end{array}$ & $\begin{array}{l}\text { Total number } \\
\text { of records } \\
\text { from countries known } \\
\text { to recommend } \\
\text { antibiotics }\end{array}$ \\
\hline South East Asia & 5 & $83 \%$ & $\begin{array}{l}\text { Proportion } \\
\text { of recommendaining } \\
\text { an antibiotic }\end{array}$ \\
Western Pacific & 2 & $100 \%$ & 1046 & 42,859 \\
America & 3 & $33 \%$ & 301 & 15,704 \\
Eastern Mediterranean & 1 & $50 \%$ & 260 & 16,102 \\
Total & 11 & 52 & 1659 & $1.92 \%$ \\
\hline
\end{tabular}

Total number of records from countries known to recommend antibiotics is 251,982 ; proportion of these records containing an antibiotic $0.66 \%$

Total number of records in the whole data set is 436,674; proportion of records containing an antibiotic $0.38 \%$

The total number of records from countries known to be recommending antibiotics grouped by region and the percentage of those records containing an antibiotic. The number of antibiotic-containing records expressed as a percentage of the whole data set and from countries known to be recommending antibiotics is also given 


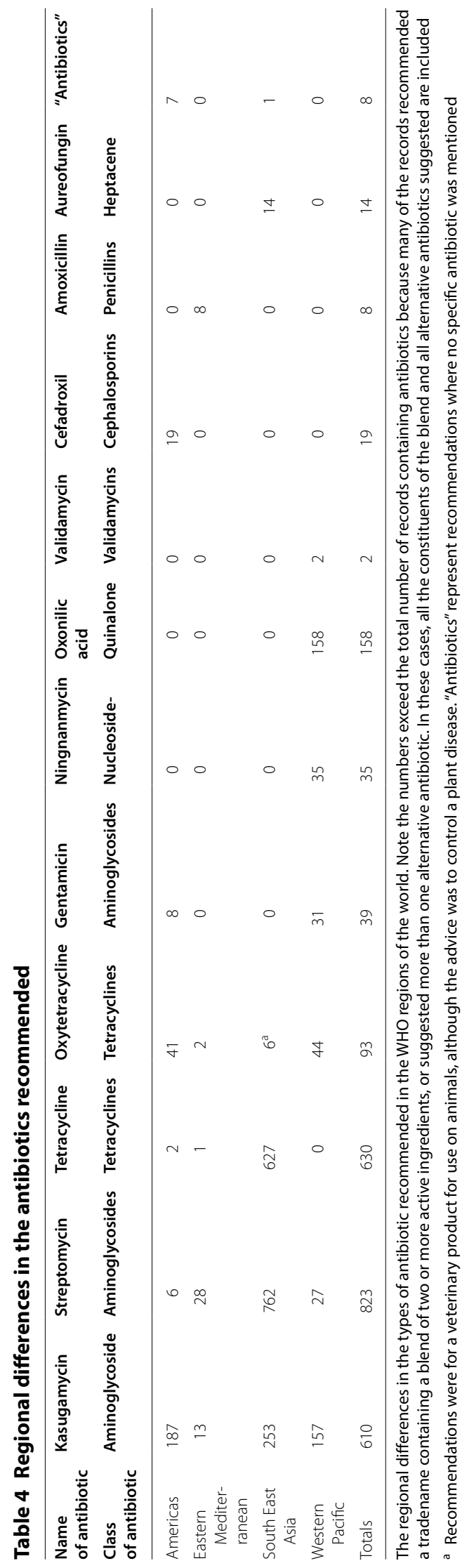


and absolute numbers were EM, Americas, WP and SEA (Table 3).

\section{What antibiotics are being recommended?}

A total of 11 antibiotics belonging to 8 classes were recorded from the data. Some of these including oxolinic acid, kasugamycin, ningnanmycin, validamycin and aureofungin are primarily used in an agricultural context, whereas others such as amoxicillin, tetracycline, oxytetracycline, streptomycin, gentamicin and cefadroxil are deemed to be medically important (World Health Organisation 2019). The type of antibiotic recommended varied considerably between the various regions (Table 4).

Overall streptomycin was the most frequently recommended antibiotic followed by tetracycline and kasugamycin. Whilst certain antibiotics such as kasugamycin were used across all regions, there were clear regional preferences for others. The SEA region was the biggest user of tetracycline and streptomycin, whereas, oxytetracycline and gentamicin were mostly used in the Americas and WP. Oxolinic acid, ningnanmycin and validamycin were used exclusively in the WP and the remaining two antibiotics cefadroxil and amoxicillin were used in Americas and EM respectively.

When making recommendations agricultural advisors provide either the product trade name or the active ingredient(s) or both. Plantomycin a blend of streptomycin and tetracycline was the most commonly recommended product amongst the seventeen trade names featured in the data set (Table 5).

\section{On which crops are antibiotics recommended?}

Antibiotics were recommended on over 100 crops, however by far the most common crop to receive an antibiotic recommendation was rice. The crops on which the antibiotics were most frequently used are shown in Table 6.

As rice was the crop on which most antibiotics were recommended this data was looked at in more detail to see if there were regional variations in antibiotic use on this crop. Although rice is commonly represented in the EM, SEA and WP regions, there are significant regional differences in the proportion of rice crop treated with antibiotics (Table 7). No rice crops were represented in the data from Americas.

Agronomic advisors in the SEA region regularly recommend antibiotics for rice problems, with over $7.4 \%$ of the recommendations on this crop containing an antibiotic. This in contrast to the EM region, where fewer than $0.2 \%$ of the recommendations on rice contained an antibiotic. Antibiotics also featured against rice problems in the WP region although overall their usage was somewhat lower than the SEA region with around $1.4 \%$ of the records on rice containing an antibiotic.

\section{What are the antibiotics being recommended against?}

An analysis of the diagnoses made by the agricultural advisor when recorded as free text revealed over 200 unique diagnoses for which antibiotics were recommended. To facilitate analysis, the diagnoses were grouped based on the type of pest/pathogen or problem. As expected the largest category are diseases known to be caused by bacterial pathogens, or where the causal bacterium itself was named (Table 8).

The relatively high number of recommendations of antibiotics against a named insect or mite is surprising, given that these compounds have no activity against these groups. The next highest grouping that received an antibiotic recommendation were a named fungus or fungal diseases.

In addition to the free text box for the diagnosis, ten check boxes were provided on the form as a means of indicating the category of organism to which the diagnosis belonged; namely Bacterium, Fungus, Insect, Mite, Nutrient deficiency, Virus, Phytoplasma, Water mould, Nematode and Weeds. To facilitate analysis the data was simplified, as there were 22 combinations of checkboxes ticked. All records with a cause indicted by a check box were amalgamated into a single category irrespective of whether there were one or more check boxes ticked. Where two or more checkboxes were ticked the record was included in all categories indicated. Thus, records with two checkboxes ticked appear in the data twice and three checkboxes three times.

Whilst it can be seen that the majority of the antibiotic recommendations were made against bacteria, there are regional variations with respect to the proportion and type of the other organisms that antibiotics are being used against (Fig. 1).

Antibiotics were recommended for managing fungal problems across all four regions, however their use for this purpose was proportionally higher in the EM where a third of the antibiotic recommendations where against fungi. Similarly about $17 \%$ of the antibiotic records in the SEA were against fungal targets. Insects and mites were also a target for antibiotic recommendations particularly in the SEA region where these constituted more than a quarter of the recommendations. Conversely, in the WP antibiotics were rarely recommended against insects contributing to just over $1 \%$ of the recommendations. No clear temporal trends in antibiotic use were observed over the 6-year timescale of the dataset (data not shown). The agricultural advisors are encouraged to provide a new form for each problem identified from the sample (for example, if the sample has both a fungal infection 
Table 5 Frequency of recommendation of tradenames and the constituent active ingredients

\begin{tabular}{|c|c|c|}
\hline Trade name & $\begin{array}{l}\text { Number } \\
\text { of recommendations }\end{array}$ & Active ingredient(s) \\
\hline Plantomycin & 602 & Streptomycin + tetracycline \\
\hline Kasumin & 382 & Kasugamycin \\
\hline Starner & 86 & Oxonilic acid \\
\hline Kasumil & 33 & Kasugamycin \\
\hline Agrimycin & 30 & Streptomycin \\
\hline Lobo 8WP & 24 & Oxytetracyline + gentamicin \\
\hline Cipadur $^{a}$ & 19 & Cefadroxil \\
\hline Naga 80SL & 16 & Ningnanmycin \\
\hline Aureofunginsol & 13 & Aureofungin \\
\hline Flare & 13 & Streptomycin \\
\hline Ychatot & 13 & Streptomycin + tetracycline \\
\hline Novaba & 13 & Ningnanmycin + kasugamycin \\
\hline Amoxtin & 8 & Amoxicillin \\
\hline Ningnastar & 7 & Ningnanmycin \\
\hline Phytomycin & 4 & Streptomycin \\
\hline Diboxylin & 3 & Ningnanmycin \\
\hline Antigold & 3 & Streptomycin + tetracycline \\
\hline Kozuma & 2 & Ningnanmycin \\
\hline
\end{tabular}

Recommendations in which the active ingredient (i.e. the antibiotic) is given without a trade name are excluded

a Cipadur is also a trade name of Cypermethrin (a commonly used pyrethroid insecticide) in Americas

Table 6 Ten crops on which antibiotics were most frequently recommended

\begin{tabular}{ll}
\hline Crop & $\begin{array}{l}\text { Cases in which antibiotic } \\
\text { was included on that crop }\end{array}$ \\
\hline Rice & 974 \\
Tomato & 143 \\
Citrus & 117 \\
Paprika & 61 \\
Potato & 36 \\
Cabbage & 35 \\
Eggplants & 25 \\
Pumpkin & 23 \\
Onions & 15 \\
Maize & 14 \\
\hline
\end{tabular}

Crop names were grouped and harmonised to allow analysis e.g. "Citrus" is an amalgamation of all named citrus crops

and an insect infestation, two forms should be filled out), however this was not always followed and approx. $7 \%$ of forms had multiple check boxes ticked for the type of organism, or no check boxes filled in at all. In addition, anomalies were also seen between the free text diagnosis field and the checkboxes, for example a diagnosis of the bacterial pathogen "Erwinia soft rot" may have had the "Fungal" check box erroneously checked.

\section{Antibiotic use in relation to area, part affected, developmental stage and severity of problem}

The option to record the area to which the recommendation relates was completed in approximately half the records. The median area across the whole data set was $0.6 \mathrm{Ha}$ indicating that most advice was provided to smallholder farmers. The data shows that antibiotics are predominantly applied to leaves of the plants with $86 \%$ of the records (where this information was given) including the, "leaves" check box. Only $8 \%$ of records had the "fruit" check box ticked and $0.7 \%$ for "flower". The developmental stage of the crop and the percentage of the crop affected was poorly completed by many of the agricultural advisors, with only $60 \%$ and $58 \%$ of records respectively recording this information. However of those records, $64 \%$ recorded the developmental stage as "intermediate" and 96\% indicated that the problem was affecting $25 \%$ of the crop stand or less.

\section{Discussion}

There are few recent publications relating to the use of antibiotics on crops and those that do exist often cite review papers that refer to earlier sources. Literature that describes contemporary use of antibiotics on plants is usually confined to that of extension literature (https ://extension.psu.edu/pear-disease-fire-blight), or reporting concerns over the development of antibiotic resistance in populations of plant pathogens (Sundin and Wang 2018; Farfán et al. 2014). Exceptions to this are two recent papers from China that provide some insights into antibiotics being recommended by extension services in the country (Zhang et al. 2017; Wan et al. 2019). These papers use information derived from plant clinics in China and suggest that antibiotics appear in between 2.5 and $4.5 \%$ of the recommendations.

The data generated through the Plantwise clinics is unique as it comes from 'grassroots' agricultural advisors, most of whom are employed by the ministries of agriculture. Unlike pesticide sales data, the information gives an insight into the knowledge of the agricultural advisors and what management options are routinely given to small scale farmers in low and middle-income countries (LMICs). The data-set is substantial, covering 32 countries and over 400,000 recommendations. Caution needs to be exercised when drawing conclusions about antibiotic use by farmers as the POMS database is of recommendations given to farmers and does not necessarily reflect the behaviour of the farmers. There has been no attempt in this study to assess what level of recommendations are enacted upon by the farmers, although 
Table 7 Recommendations of antibiotics on rice by regions and year

\begin{tabular}{|c|c|c|c|c|c|c|}
\hline \multirow[t]{2}{*}{ Year } & \multicolumn{2}{|c|}{ Western Pacific } & \multicolumn{2}{|c|}{ Eastern Mediterranean } & \multicolumn{2}{|c|}{ South East Asia } \\
\hline & & $\begin{array}{l}\text { Percentage } \\
\text { of recommendations } \\
\text { containing an antibiotic }\end{array}$ & & $\begin{array}{l}\text { Percentage } \\
\text { of recommendations } \\
\text { containing an antibiotic }\end{array}$ & & $\begin{array}{l}\text { Percentage } \\
\text { of recommendations } \\
\text { containing an antibiotic }\end{array}$ \\
\hline 2018 & $5 / 106$ & $4.72 \%$ & $2 / 2427$ & $0.08 \%$ & $138 / 1590$ & $8.68 \%$ \\
\hline 2017 & $6 / 556$ & $1.10 \%$ & $1 / 4883$ & $0.02 \%$ & $202 / 3144$ & $6.43 \%$ \\
\hline 2016 & 29/1095 & $2.65 \%$ & $0 / 1804$ & $0 \%$ & $195 / 2687$ & $7.26 \%$ \\
\hline 2015 & $14 / 2472$ & $0.57 \%$ & $1 / 1547$ & $0 \%$ & $278 / 2861$ & $9.72 \%$ \\
\hline 2014 & $50 / 2040$ & $2.45 \%$ & $6 / 1603$ & $0.06 \%$ & $20 / 724$ & $2.76 \%$ \\
\hline 2013 & $8 / 1396$ & $0.57 \%$ & 9/1987 & $0.45 \%$ & $6 / 351$ & $1.71 \%$ \\
\hline 2012 & $0 / 264$ & $0 \%$ & $0 / 147$ & 0 & $4 / 42$ & $9.52 \%$ \\
\hline Total & $112 / 7929$ & $1.41 \%$ & $19 / 14,398$ & 0.13 & $843 / 11,399$ & $7.39 \%$ \\
\hline
\end{tabular}

The number of recommendations containing antibiotics expressed as proportion of all the recommendations on rice segregated by year and region. Note: the Americas do not appear in this table as no rice from this region features in the data

Table 8 Grouping of antibiotic-containing recommendations according to the pathogen/pest or problem recorded in the written diagnosis

\begin{tabular}{lc}
\hline Grouping of diagnosis & Count \\
\hline Named bacterial disease or bacterium & 1038 \\
Named insect or mite & 311 \\
Named fungus or fungal disease & 155 \\
Symptoms only & 49 \\
Blank & 37 \\
Nutrient deficiency & 7 \\
Water mould & 5 \\
Virus & 3 \\
Phytoplasma & 1 \\
Weeds & 1 \\
\hline
\end{tabular}

Written diagnoses were recorded within POMS as free text. To assist analysis these were grouped by causal agent. Local names of diseases and pests often required interpretation as these were extremely colloquial and regional

previous studies in Plantwise suggest that rates of adoption of advice by farmers attending clinics, particularly of chemical control measures, are high (Silvestri et al. 2019). Despite this caveat, these data appear to indicate that the use of antibiotics in crop production is more extensive than most of the literature would suggest. Given the dearth of other sources of information, particularly from LMICs we believe that the Plantwise POMS database is an important resource in assessing the level of antibiotic use in countries where it is not monitored and regulations are either minimal or not enforced.

\section{Extent of antibiotic use}

Calculations of global antibiotic use in crops are based almost exclusively from data obtained from the USA against fire blight caused by Erwinia amylovora on apple and pear (Gusberti et al. 2015; McManus 2014; Vidaver
2002; McManus and Stockwell 2000). This literature suggests that the amount of antibiotics used for crops in the USA is relatively low, in comparison to the quantities used in livestock and aquaculture, with estimates ranging from $0.26 \%$ to $0.5 \%$ of total agricultural antibiotic consumption (McManus et al. 2002; McManus 2014). This has led authors to conclude that curtailing antibiotics use on crops would not lead to a major reduction in world use (FAO and WHO 2019a). However, the lack of surveillance programs, in many countries, combined with the lack of application records, frustrates any attempts to estimate the real amounts of antibiotics being applied. Where in-depth studies have been undertaken results may be surprising. In Costa Rica it has been suggested that the amounts of tetracycline and gentamicin used in on crops may be 200-700 times the quantities used in human medicine (Rodríguez Sánchez 2008).

Throughout this study the data is divided into the regions based on the WHO classification system and countries are not identified individually so as to protect national identity, whilst providing some insight into the use of antibiotics. Not only is there extreme variation between the regions, as seen from the results presented (Africa with no use at all and SEA with nearly $2.5 \%$ of all recommendations containing an antibiotic), but there is enormous variation in the amounts of antibiotics used by various countries within the regions; data not disclosed. The regional and national differences in antibiotic recommendations may be due to price, legislation, product availability, cropping regimes, agronomic advisors' knowledge, or the nature of the pathogens that are problems. It can only be speculated as to which combination of these factors causes the differential in antibiotic use.

Sundin and Wang (2018) suggest that antibiotics are not more widely used because of the expense involved, 


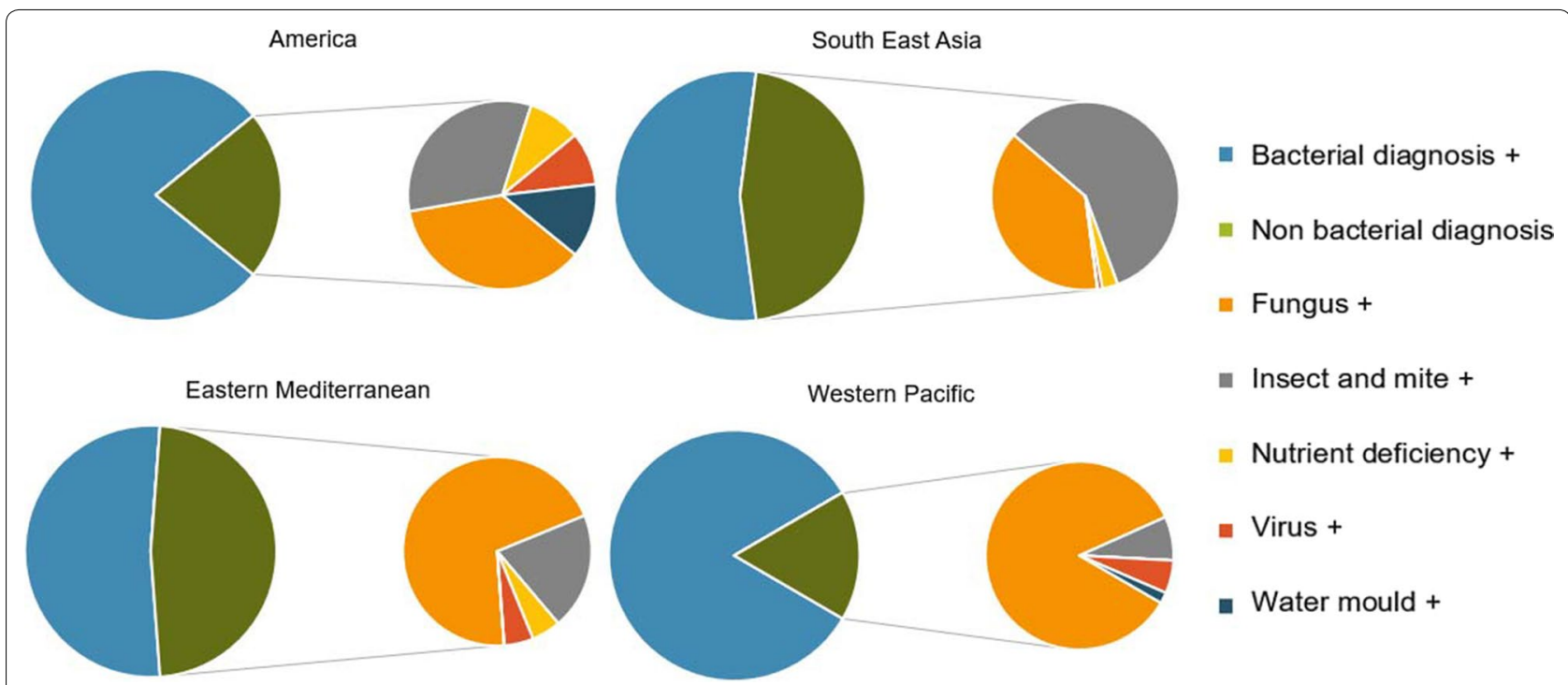

Fig. 1 Proportions of diagnoses against which antibiotics are recommended based on checkbox data. In each pair of pie charts the larger one represents the proportion of antibiotic recommendations made against either bacterial or non-bacterial problems. The smaller chart breaks down the non-bacterial diagnoses into its subcomponents based the check boxes ticked. Note records that contained more than one check box (indicating multiple problems) are marked with a" + " and this data appears more than once in the chart e.g. a record that had the virus and fungus boxes ticked would appear in the "Virus+" and the "Fungus+" categories. Data from "Insect" and "Mite" check boxes were combined and an isolated record of "Weed" is not represented in the figure

but that does not appear to be the case as the bulk costs of tetracycline and streptomycin are available at $\$ 10$ and $\$ 1$ per kilo respectively, a similar price to copper oxychloride (Alibaba.com price correct as of 2019). However, it is interesting to note that within the data set there are no antibiotics recommended in the African countries.

Bacterial pathogens are present throughout the world and on all crops. Given the variety of crops and cropping systems used across the African continent it is considered unlikely that the types of pathogens encountered in Africa are sufficiently different from the remainder of the world. In many LMICs, including those in Africa, antibiotics are freely available through unregulated supply chains and over-the-counter sales. It is therefore unlikely that the discrepancy in antibiotic use in Africa as compared to other regions of the world is due to their unavailability. This would indicate that some other factor(s) are preventing (or limiting) antibiotic use in this region. In China, the use of antibiotics in crop production is higher than that recorded within our data (Zhang et al. 2017). Of the recommendations made by cooperative based extension workers $4.5 \%$ of them contained an antibiotic (Zhang et al. 2017). The use of antibiotics on crops in China is at least partially fuelled by government subsidies aimed at promoting their use (Zhang et al. 2017).

\section{What crops are antibiotics being used on ?}

Within the data, rice dominates the crops on which antibiotics are recommended and it is not possible to determine if that is due to the nature of the crop or the countries in which it is grown. The preponderance of antibiotic-containing recommendations on rice in SEA dominates the regional differences within the data. In SEA $7.4 \%$ of the recommendations for rice appeared to contain an antibiotic and, in some years, this was nearly $10 \%$. When rice is removed from the calculations the proportion of recommendations containing an antibiotic in SEA was reduced to a much more modest $0.6 \%$. The next greatest consumer of antibiotics are the Americas with $1.62 \%$ of all recommendations containing an antibiotic, despite no rice appearing in the POMS data. It would appear that for some reason antibiotic application on rice in SEA is prolific relative to other rice growing areas and other crops. However, research workers in one SEA country claim that the use of antibiotics on rice is relatively minor and is dwarfed by that used on ornamental crops for religious purposes. The residue of tetracycline was clear to see on a rose on a recent visit to the region by the lead author (Fig. 2).

\section{Which antibiotics are being used?}

The 18 tradenames of antibiotic products within the POMS dataset is only fraction of that available to treat crop diseases in many areas of the world (especially in the 


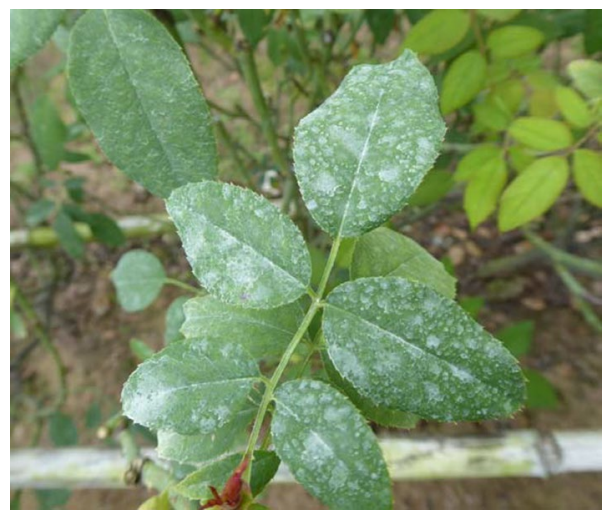

Fig. 2 Spray residue on rose follow a recent spraying of Thiophanate-methyl and a streptomycin/tetracycline blend in SEA. The spraying of antibiotics onto crops used for religious purposes was very common in one SEA country. The doses suggested by the manufacturer were often increased many times

WP Region). Of the eleven antibiotics contained within the data, 6 of them (streptomycin, tetracycline, oxytetracycline, gentamicin, cefadroxil, amoxicillin) are considered to be critically important antimicrobials for human medicine as defined by the WHO (World Health Organisation 2019). The other antibiotics (oxolinic acid, kasugamycin, ningnanmycin, validamycin and aureofungin) are restricted to use in agricultural settings against bacterial, and in some cases, fungal diseases.

\section{Regional differences}

Our results confirm that of others, indicating that streptomycin is the most commonly used antibiotic on crop plants (McManus 2014; Zhang et al. 2017) with tetracycline and kasugamycin in second and third position. Interestingly, the antibiotic zhongshengmycin, does not appear in our data, despite it being the second most widely recommended antibiotic in Chinese plant clinics (over a quarter of antibiotic recommendations) (Zhang et al. 2017).

Kasugamycin was widely used in all regions, but the use of other antibiotics shows considerable regional variation with six of the 11 antibiotics only appearing in one region. Despite the large number of records from SEA, only 3 antibiotics form the bulk of the data (99\%), namely kasugamycin, streptomycin and tetracycline. Almost all of the kasugamycin used in SEA was on rice (only $14 \%$ on non-rice crops) and yet kasugamycin was the antibiotic of choice in America ( $72 \%$ of all records containing an antibiotic), yet there are no records of rice being brought to clinics in the data from the Americas.

Other antibiotics show similar regional restrictions, for example oxolinic acid was used in the WP (35\% of all antibiotic recommendations), but nowhere else, similarly in SEA 38\% of recommendations contain tetracycline, yet this antibiotic only appears on three occasions outside of this region. Indeed, we speculate that records of "tetracycline" in areas outside of SEA are actually an abbreviation of "oxytetracycline".

It is considered unlikely that the regional variation in antibiotics is due to their specificity against the bacterial diseases of the region. However, resistance to an antibiotic may be driving some of the differences, as farmers turn to alternatives when products become ineffective (Manulis et al. 1999; Goodman 1980). Alternatively, regional differences may be due to manufacturers initial selection, production facilities and marketing. The huge variation (orders of magnitude) in the use of antibiotics between similar countries that border each other (data not shown) is interesting in itself, but it also throws doubt on the legitimacy of extrapolating antibiotic use from one country to another (Van Boeckel et al. 2015).

\section{What problems are the antibiotics being recommended against?}

Antibiotics are generally used against bacterial pathogens in both medical and veterinary settings. Based on the written diagnosis about $60 \%$ of the diagnoses were against a named bacterium or a bacterial disease (64\% when based on checkboxes). It is reasonable to assume that in most of these cases the application of antibiotics would have been beneficial to the health of the crop, but in $6 \%$ of the cases, where the diagnosis was "bacterial wilt", a spray antibiotic treatment would not have had any effect.

The second largest category of organisms where antibiotics were recommended was against insects and/or mites $12 \%$ (18\% when based on checkboxes). This is surprising as antibiotics have no activity against arthropods. The use of antibiotics against insects and mites is particularly prevalent in SEA, which accounted for over $90 \%$ of antibiotic recommendations against this group. In addition to antibacterial effects some antibiotics including, streptomycin, kasugamycin, aureofungin, ningnanmycin, oxolinic acid and validamycin have activity against other pathogen groups including fungi (Vallad et al. 2010; Lee et al. 2005), water moulds (Tso and Jeffrey 1956) and viruses (Han et al. 2014).

Antibiotics were recommended for managing fungal problems in all four regions, however the practice was most prevalent in the EM and SEA regions where $33 \%$ and $17 \%$ of records containing an antibiotic were against fungal targets respectively. It is not possible to determine to what extent agricultural advisors are aware of the antifungal activity of some of the antibiotics, but there is evidence from the data to suggest awareness for at least some pathogen/crop combinations. An example 
of this was the use of aureofungin for Ganoderma (fungal pathogen) control in coconut. This antibiotic has antifungal activity and is an established management practice for this disease (Kandan et al. 2010). In SEA all but two of the records featuring aureofungin were for Ganoderma management.

Kasugamycin is an agricultural antibiotic originally developed for use in rice with action against the fungal disease, rice blast (Mangnaporthe oryzae). In SEA, when kasugamycin was recommended against a fungal problem it was almost exclusively against rice blast, whereas this antibiotic was not recommended against fungal diseases of rice in any other region. Streptomycin and tetracycline were also recommended against rice blast in SEA despite them having no effect on this disease, perhaps pointing to a misunderstanding of the properties of these two antibiotics.

It is a common misconception in human medicine that antibiotics can kill viruses (Jordan 2014), but that does not appear to translate into recommendations that relate to crop production. Based on checkboxes, $4.4 \%$ of all records in the entire data set (not just those for which an antibiotic has been recommended) are solely for a viral disease, whereas of the records that feature an antibiotic in the recommendation only $0.54 \%$ are deemed to be caused by a virus. Interestingly the antibiotic ningnanmycin has, in experimental studies, demonstrated some antiviral activity (Han et al. 2014). However, in our data ningnanmycin was restricted to relatively few records in the SEA region and none of these were against viral problems. It is clear that in some cases antibiotics are being used effectively against non-bacterial targets however, their profligate use could lead to the conclusion that agricultural advisors are unaware of their limited spectrum of activity. However, it was observed that in many cases, especially in SEA, the recommendations were identical regardless of the diagnosis. We speculate that the agricultural advisors in SEA routinely combine an insecticide with a fungicide and an antibiotic in a single application so as to deal with the current issue and to prevent/control other problems not yet present or residing at a low level.

\section{Stage of development severity and area treated with antibiotics}

The focus of the Plantwise programme is to assist the advisors of smallholder farmers and this was indeed the case as the plot size to which the recommendations refer had a median size of $0.6 \mathrm{Ha}$. The mean area is not quoted as it is potentially misleading due to what appear to be misplaced decimal points on the plantwise forms. Antibiotics are applied to crops midway through their production as the vast majority of antibiotic applications were on crops that were in the "intermediate" stage of growth and were applied to the "leaves" of the plants. Less than $5 \%$ of the records related to treatment of seedlings. Interestingly there were five records recommending postharvest application of antibiotics which obviously raises concerns over residues levels for consumers. When considering the severity of attack, $96 \%$ of the records indicated that the diagnosed problem was affecting a quarter or less of the crop stand indicating that antibiotics are used before the problem has become widely established.

\section{Doses of antibiotic}

The concentration of antibiotic applied and the actual dose received by the leaves depends on the amount of water used to dilute the concentrate, as run-off will soon be reached if the crop were young, or if the volume of spray were too high. However, this would not affect the total amount of antibiotic being sprayed into the environment. To estimate the amount of antibiotics being applied it is useful to pick a crop and region and examine in more detail how much product is applied. In the SEA region $7.4 \%$ of all recommendations on rice contained an antibiotic. Plantomycin (the most widely recommended antibiotic in the region) is a mixture of streptomycin and tetracycline. For the basis of this calculation it was assumed that the recommended rate was applied to $7.4 \%$ of the entire rice growing area of the region (estimated to be in excess of 75 million $\mathrm{Ha}$ (http://ricestat.irri.org:8080/ wrsv3/entrypoint.htm). If this were the case then a single application would represent over 63 tonnes of streptomycin and 7 tonnes of tetracycline. This may well be an underestimate as the manufacturers recommended dose is frequently doubled by the agricultural advisors.

These data are just a small snapshot of chemical applications, and these amounts are relatively small compared to the livestock sector, but nevertheless significant especially when their environmental fate is considered.

\section{What other control methods are used against bacterial plant pathogens?}

Unlike the vast arsenal of chemicals active against fungi and water moulds ( 85 in the entire dataset) there are relatively few chemicals represented that are effective in reducing bacterial diseases. Some fungicides such as Mancozeb have limited action against bacterial diseases and there are specialist bactericidal compounds such as Bronopol and Bismerthiazol, but based on our data these are not widely used. Bismerthiazol is often blended with antibiotics, indeed there are 6 products commercially available in Vietnam which comprise Bismerthiazol blended with antibiotics (Noghiệp bộ nông và phát triển nông thôn [Ministry of Agricultural Development] 2016).

Our data would suggest that by far the most widely used chemical against bacterial diseases are copper salts. 
In the entire data set over $13 \%$ of records that have the "Bacterial" checkbox ticked have the word "copper" in the recommendation. This however, is a considerable underestimate of copper-based products as many are recommended by trade name only, or as "Bordeaux mixture". The proportion of records that contain an antibiotic and the word "copper" is $21 \%$ (again an underestimate). It is common for copper salts to be preblended with antibiotics and in Vietnam alone there are over 9 products (not represented in the POMS dataset) that are antibacterial chemicals comprising a blend of antibiotics and copper salts (Noghiệp bộ nông và phát triển nông thôn [Ministry of Agricultural Development] 2016).

Copper salts are a very widely used active ingredient, popular with agricultural advisors as they are commonly available and active against fungal, water mould and bacterial diseases. These antimicrobial properties make it a popular choice amongst agricultural advisors, especially if they are unable to make a definitive diagnosis, as a copper containing product will have a beneficial effect against all these classes of pathogen.

\section{Spread of antibiotic resistance to animal and human pathogens}

There is great concern over the use of antibiotics in agriculture due to the potential for resistance to spread to medically important bacteria. Most of the concern has been based around the use of antibiotics in animal husbandry and the use within crop production has largely not been commented upon, possibly because the use is thought to be very low in comparison to the quantities used in livestock, or because the medical community were unaware of their use in this regard. The regulations pertaining to antibiotic use on plants differs widely between countries and regions. The European Union and Brazil do not approve any antibiotics as active ingredients in pesticides (Donley 2019), whereas some countries permit their use for certain crops or in emergency situations, others have no legislation on this topic at all. Moreover, many countries of SEA and WP, consider the use of antibiotics in crop production as an important means of controlling pathogens whilst at the same time protecting the environment.

It is only recently that international bodies such as FAO and WHO have started to raise concerns over the use of antibiotics in the management of crop diseases. In a recent joint meeting on pesticide management, a recommendation was made that antibiotics used for human and animal health should not be registered as pesticides (FAO and WHO 2019b). These concerns relate to antibiotic use creating selection pressure in a cropping environment that accelerates the spread of antibiotic resistance from soil bacteria to human pathogens. However, the full extent to which antibiotic use in these systems accelerates the emergence of antibiotic resistance in zoonotic pathogens present on crops is yet to be determined (FAO and WHO 2019c).

There is however good evidence to suggest that crops (especially those eaten raw) are a potential vehicle for resistant bacteria to enter the human gut (Boehme et al. 2004; Hassan et al. 2011; Raphael et al. 2011; Rodríguez et al. 2006; Ruimy et al. 2010; Schwaiger et al. 2011; Walia et al. 2013). Some authors even suggest that these resistant bacteria could be a source of genetic material for lateral gene transfer subsequent to ingestion, giving rise to antibiotic resistant pathogens in the gut (Bezanson et al. 2008).

One unique aspect of antibiotic use on crops is that they are routinely mixed with other agrochemicals. This use has led to concerns over interactions that might promote cross-resistance or co-selection for antibiotic resistance. One study demonstrated that bacteria develop antibiotic resistance up to 100,000 times faster when exposed to certain herbicides/antibiotic mixtures relative to exposure to antibiotics alone (Kurenbach et al. 2018). Preblended, or on-farm blends of antibiotics and copper salts similarly give cause for concern as soil bacterial communities from soil contaminated with copper have been reported to be significantly more tolerant to vancomycin and tetracycline than control soil bacterial communities (Pal et al. 2015). Additionally, bacteria harbouring genes conferring resistance to certain metal ions including copper are significantly more likely to also have genes for antibiotic resistance as compared to bacteria without metal resistance genes (Pal et al. 2015). Thus, despite the relatively low amounts of antibiotics used in crop production their use in combination with other plant production products represent a potentially important risk factor for selection and dissemination of resistant microorganisms and genes from plants to humans and animals.

This said, those who advocate the use of antibiotics to control plant diseases point out that there is no proven evidence of resistance having spread from plant pathogenic bacteria to human or animal pathogens despite over 50 years of continual use. Indeed one study reports that the proportion of antibiotic resistant bacteria was greater in an orchard that had not been sprayed with antibiotics as compared to one that had received regular antibiotic sprays (Yashiro and McManus 2012).

\section{Conclusions}

The data presented in this paper gives a unique perspective on the amount and types of antibiotics being recommended to small scale farmers by 'grassroots' agricultural advisors, in low and middle-income countries. Studies 
into the use of antibiotics in crop protection have been largely neglected and there is a general dearth of information, particularly from LMICs. We believe that the Plantwise POMS database is an important resource in assessing the level of antibiotic use in countries where it is not monitored and regulations are either minimal or not enforced.

We found that antibiotics were being recommend for the management of plant health problems in the WHO regions of, the Americas; Western Pacific; Eastern Mediterranean and South East Asia, but there was no evidence of their use in Africa. There was however, enormous variation in the amounts of antibiotics recommended by various countries within the regions.

Rice dominated the crops on which antibiotics were recommended, particularly in the SEA region where $7.4 \%$ of the recommendations for this crop appeared to contain an antibiotic and, in some years, this was nearly $10 \%$. Approximately $60 \%$ of the diagnoses were against a named bacterium or a bacterial disease, however antibiotics were also recommended against fungal problems, for which some have activity. The use of antibiotics against insects and mites was also recorded in the data, particularly in the SEA region. We speculate that the agricultural advisors in this region use antibiotics prophylactically, combining them with other crop protection products to prevent/control other problems not yet present, or residing at a low-levels.

There is great concern over the use of antibiotics in agriculture due to the potential for resistance to spread to medically important bacteria and six of the eleven antibiotics contained within the data (streptomycin, tetracycline, oxytetracycline, gentamicin, cefadroxil, amoxicillin) are considered by the WHO to be critically important antimicrobials for human medicine. Whilst the use of antibiotics in crop production appears modest compared to animal production it is potentially more widespread than previously thought. Further research into the scale of antibiotic use in crop protection is warranted and the potential for interactions with other crop protection products that might promote cross-resistance or co-selection for antibiotic resistance.

Most HICs are well aware of the over-use and misuse of antibiotics and there are increasingly reports from wellrespected international organisations calling for cooperation often under the banner of one health. The concept of one health includes animal and human health, but plant health is often excluded. It is hoped that the data presented in this paper will increase the debate regarding the use of antibiotics against crop pathogens and that crop production will be included under the one health umbrella. This important data set is growing and will enable us to monitor the use of antibiotics in crop production in the future. It is our intention that it will enable the scientific community and legislators to steer a pragmatic and rational approach to the use of antibiotics.

\section{Abbreviations}

EM: Eastern Mediterranean; FAO: Food and Agriculture Organisation; HIC: High income countries; IPM: Integrated Pest Management; LMIC: Low and middleincome countries; OIE: World Organisation for Animal Health; POMS: Plantwise Online Management System; SEA: South East Asia; WHO: World Health Organisation; WP: Western Pacific.

\section{Acknowledgements}

The authors would like to acknowledge the work of Josh Cole of the University of Warwick who was instrumental in the analysis of the raw data.

\section{Authors' contributions}

Both authors were instrumental in all aspects of the analysis and production of the manuscript. Both authors read and approved the final manuscript.

\section{Funding}

We gratefully acknowledge the funding provided for this research, through the Plantwise programme, by the following agencies: Department for International Development, UK; Swiss Agency for Development and Cooperation; Directorate General for International Cooperation, Netherlands; European Commission; Ministry of Agriculture of the People's Republic of China; Irish Aid; International Fund for Agricultural Development; and Australian Centre for International Agricultural Research. CABI also acknowledges its core financial support from its member countries and lead agencies (see http://www.cabi. org/about-cabi/who-we-work-with/key-donors/).

\section{Availability of data and materials}

The datasets used in this article are not available due to national confidentiality.

\section{Ethics approval and consent to participate}

Not applicable.

\section{Consent for publication}

Not applicable.

\section{Competing interests}

The authors declare that they have no competing interests.

Received: 16 January 2020 Accepted: 30 March 2020

Published online: 23 June 2020

\section{References}

Bezanson GS, MacInnis R, Potter G, Hughes T. Presence and potential for horizontal transfer of antibiotic resistance in oxidase-positive bacteria populating raw salad vegetables. Int J Food Microbiol. 2008;127(1-2):37-42.

Boehme S, Werner G, Klare I, Reissbrodt R, Witte W. Occurrence of antibioticresistant enterobacteria in agricultural foodstuffs. Mol Nutr Food Res. 2004;48(7):522-31.

Danielsen S, Matsiko FB. Using a plant health system framework to assess plant clinic performance in Uganda. Food Secur. 2016;8(2):345-59.

Discover more about our plant clinic network-Plantwise. https://www.plant wise.org/about/. Accessed date 2 Dec 2019.

Donley N. The USA lags behind other agricultural nations in banning harmful pesticides. Environ Heal. 2019;18(1):44.

FAO. Antimicrobial resistance in food and agriculture; 2017. http://www.fao.org/ antimicrobial-resistance. Accessed 2 Dec 2019.

FAO and WHO. Monitoring global progress on addressing antimicrobial resistance; 2019a. p. 66. https://apps.who.int/iris/bitstream/handle/10665/27312 8/9789241514422-eng.pdf?ua=1. Accessed Apr 2019.

FAO and WHO. Expert Meeting in collaboration with OIE on Foodborne Antimicrobial Resistance: Role of the Environment, Crops and Biocides-Meeting 
report. Environment, Crops and Biocides MEETING REPORT. Rome: Microbiological Risk Assessment Series no. 34.; 2019b. www.fao.org/publications. Accessed 9 Dec 2019.

FAO and WHO. Report 11th FAO/WHO Joint Meeting on Pesticide Management 9-12 October 2018 Rome; 2019c.

Farfán LM, Benítez SV, Carvajal LMH. Sensibilidad de bacterias procedentes de pasifloras a antibióticos y productos cúpricos. Rev Colomb Ciencias Hortícolas. 2014;8(1):20-33.

Goodman RN. The effects on human health of subtherapeutic use of antimicrobials in animal feeds. In: Appendix B possible human health effects of subtherapeutic antimicrobial use as pesticides. National Academies Press (US); 1980. https://www.ncbi.nlm.nih.gov/books/NBK216505/. Accessed 2 Dec 2019.

Gusberti M, Klemm U, Meier MS, Maurhofer M, Hunger-Glaser I. Fire blight control: the struggle goes on. A comparison of different fire blight control methods in Switzerland with respect to biosafety, efficacy and durability. Int J Environ Res Public Health. 2015;12(9):11422-47.

Han Y, Luo Y, Qin S, Xi L, Wan B, Du L. Induction of systemic resistance against tobacco mosaic virus by Ningnanmycin in tobacco. Pestic Biochem Physiol. 2014:111(1):14-8.

Hassan SA, Altalhi AD, Gherbawy YA, El-Deeb BA. Bacterial load of fresh vegetables and their resistance to the currently used antibiotics in Saudi Arabia. Foodborne Pathog Dis. 2011;8(9):1011-8.

Jacobs A. Citrus Farmers Facing Deadly Bacteria Turn to Antibiotics, Alarming Health Officials_-The New YorkTimes. The New YorkTimes; 2019. https:// www.nytimes.com/2019/05/17/health/antibiotics-oranges-florida.html. Accessed 8 Oct 2019.

Jordan W. 41\% of adults think antibiotics kill viruses / YouGov; 2014. https://yougo v.co.uk/topics/politics/articles-reports/2014/07/08/41-adults-think-antib iotics-kill-viruses. Accessed 2 Dec 2019.

Kandan A, Bhaskaran R, Samiyappan R. Ganoderma - a basal stem rot disease of coconut palm in south Asia and Asia pacific regions. Arch Phytopathol Plant Prot. 2010;43(15):1445-9.

Kurenbach B, Hill AM, Godsoe W, Van Hamelsveld S, Heinemann JA. Agrichemicals and antibiotics in combination increase antibiotic resistance evolution. PeerJ. 2018;6(10):e5801.

Lee HB, Kim Y, Kim JC, Choi GJ, Park S-H, Kim C-JC-J, Jung HS. Activity of some aminoglycoside antibiotics against true fungi, Phytophthora and Pythium species. J Appl Microbiol. 2005;99(4):836-43.

Manulis S, Zutra D, Kleitman F, Dror O, Shabi E, Zilberstaine M, David I. Streptomycin resistance of Erwinia amylovora in Israel and occurrence of fire blight in pear orchards in the autumn. Acta Hortic. 1999;489:85-92.

McManus PS. Does a drop in the bucket make a splash? Assessing the impact of antibiotic use on plants. Curr Opin Microbiol. 2014;19(1):76-82.

McManus P, Stockwell V. Antibiotics for plant diseases control: silver bullets or rusty sabers. APSnet Featur Artic; 2000.

McManus PS, Stockwell VO, Sundin GW, Jones AL. Antibiotic use in plant agriculture. Annu Rev Phytopathol. 2002;40:443-65.

Noghiệp bộ nông và phát triển nông thôn [Ministry of Agricultural Development]. Ban hành danh mục thuốc bảo vệ thực vật được phép sử dụng, cấm sử dụng tại việt nam; công bố mã hs đối với thuốc bảo vệ thực vật được phép sử dụng, cấm sử dụng tại việt nam [Promulgate a list of plant protection drugs permitted for use and banned for use in Vietnam; Announcing HS code for plant protection drugs allowed to be used and banned for use in Vietnam; 2016. https://www.vietnamtradeportal.gov.vn/ kcfinder/upload/files/03.2016.TT-BNNPTNT.pdf. Accessed 5 Dec 2019.

O'Neill J. Antimicrobials in agriculture and the environment: reducing unnecessary use and waste; 2015. http://amr-review.org/sites/default/files/Antim icrobialsinagricultureandtheenvironment-Reducingunnecessaryuseand waste.pdf. Accessed 8 Oct 2019.

Pal C, Bengtsson-Palme J, Kristiansson E, Larsson DGJ. Co-occurrence of resistance genes to antibiotics, biocides and metals reveals novel insights into their co-selection potential. BMC Genomics. 2015;16(1):964.

Palmer EL, Teviotdale BL, Jones AL. A relative of the broad-host-range plasmid RSF1010 detected in Erwinia amylovora. Appl Environ Microbiol. 1997:63(11):4604-7.

Patil B, Naik S. Management of bacterial leaf blight of rice caused by Xanthomonas oryzae pv. oryzae under field condition. J Pharmacogn Phytochem. 2017;6(6):244-6.

PennState Extension. Pear disease-fire blight. https://extension.psu.edu/peardisease-fire-blight. Accessed 8 Oct 2019.
Raphael E, Wong LK, Riley LW. Extended-spectrum beta-lactamase gene sequences in Gram-negative saprophytes on retail organic and nonorganic spinach. Appl Environ Microbiol. 2011;77(5):1601-7.

Rodríguez Sánchez C. Oxytetracycline and gentamicin: two clinicallyrelevant antimicrobials widely used by costa rican farmers. Implications of their use outside clinical cettings and request for action. Rev Médica la Univ Costa Rica. 2008;2(2):64-71.

Rodríguez C, Lang L, Wang A, Altendorf K, García F, Lipski A. Lettuce for human consumption collected in Costa Rica contains complex communities of culturable oxytetracycline- and gentamicin-resistant bacteria. Appl Environ Microbiol. 2006;72(9):5870-6.

Ruimy R, Brisabois A, Bernede C, Skurnik D, Barnat S, Arlet G, et al. Organic and conventional fruits and vegetables contain equivalent counts of Gramnegative bacteria expressing resistance to antibacterial agents. Environ Microbiol. 2010;12(3):608-15.

Schwaiger K, Helmke K, Hölzel CS, Bauer J. Antibiotic resistance in bacteria isolated from vegetables with regards to the marketing stage (farm vs supermarket). Int J Food Microbiol. 2011;148(3):191-6.

Silvestri S, Macharia M, Uzayisenga B. Analysing the potential of plant clinics to boost crop protection in Rwanda through adoption of IPM: the case of maize and maize stem borers. Food Secur. 2019;11(2):301-15.

Smith et al, Tim David Granatstein, Ken Johnson TD. Fire Blight | WSU Tree Fruit | Washington State University. http://treefruit.wsu.edu/crop-protection/disea se-management/fire-blight/. Accessed 2 Dec 2019.

Stockwell VO, Duffy B. Use of antibiotics in plant agriculture. Rev Sci Tech. 2012;31(1):199-210.

Sundin GW, Wang N. Antibiotic resistance in plant-pathogenic bacteria. Annu Rev Phytopathol. 2018:56:161-80.

Tso TC, Jeffrey RN. Effect of antibiotics on the growth and alkaloid production of tobacco plants [7]. Nature. 1956;178:800-1.

Vallad GE, Pernezny KL, Balogh B, Wen A, Figueiredo JFL, Jones JB, et al. Comparison of kasugamycin to traditional bactericides for the management of bacterial spot on tomato. HortScience. 2010;45(12):1834-40.

Van Boeckel TP, Brower C, Gilbert M, Grenfell BT, Levin SA, Robinson TP, et al. Global trends in antimicrobial use in food animals. PNAS. 2015;18:5649-54

Vidaver AK. Antimicrobials in plant agriculture CID 2002:34 (Suppl 3) S107 uses of antimicrobials in plant agriculture. https://academic.oup.com/cid/artic le-abstract/34/Supplement_3/S107/292699.

Walia S, Rana SW, Maue D, Rana J, Kumar A, Walia SK. Prevalence of multiple antibiotic-resistant Gram-negative bacteria on bagged, ready-to-eat baby spinach. Int J Environ Health Res. 2013;23(2):108-18.

Wan M, Gu R, Zhang T, Zhang Y, Ji H, Wang B, et al. Conflicts of interests when connecting agricultural advisory services with agri-input businesses. Agriculture. 2019;9(10):218.

World Health Organisation. WHO list of critically important antimicrobials for human medicine (WHO CIA list), 6th revision. Geneva: World Health Organization; 2019. http://who.int/foodsafety/publications/antimicrobials-fifth/ en/. Accessed 2 Dec 2019

World Health Organization, Food and Agriculture Organization of the United Nations, World Organisation for Animal Health. Monitoring Global Progress on Addressing Antimicrobial Resistance: analysis report of the second round of results of AMR country self-assessment survey 2018; 2018. http://www. fao.org/3/ca0486en/CA0486EN.pdf. Accessed Apr 2019.

World Rice Statistics Online Query Facility. http://ricestat.irri.org:8080/wrsv3/entry point.htm. Accessed 8 Oct 2019.

Yashiro E, McManus PS. Effect of streptomycin treatment on bacterial community structure in the apple phyllosphere. PLoS ONE. 2012;7(5):e37131.

Yau S, Liu X, Djordjevic SP, Hall RM. RSF1010-like plasmids in Australian Salmonella enterica serovar typhimurium and origin of their sul2-strA-strB antibiotic resistance gene cluster. Microb Drug Resist. 2010;16(4):249-52.

Zhang T, Toepfer S, Wang B, Peng H, Luo H, Wan X, et al. Is business linkage affecting agricultural extension service quality? Int J Agr Ext. 2017;5:59-77.

\section{Publisher's Note}

Springer Nature remains neutral with regard to jurisdictional claims in published maps and institutional affiliations. 